\title{
Publisher Correction: Dark nights bring a bright dawn
}

Paul Woods

Correction to: Nature Astronomy https://doi.org/10.1038/s41550-018-0535-8, published online 3 July 2018.

In the version of this Editorial originally published, the meaning of the last sentence in the first paragraph wasn't clear and it has been changed from 'Other repositories of wealth include oil, minerals and most valuably, people: consumers and labourers.' to 'Other repositories of wealth include oil, minerals and most valuably, people - acting both as consumers and as employees in a workforce.'

Published online: 11 July 2018

https://doi.org/10.1038/s41550-018-0545-6 